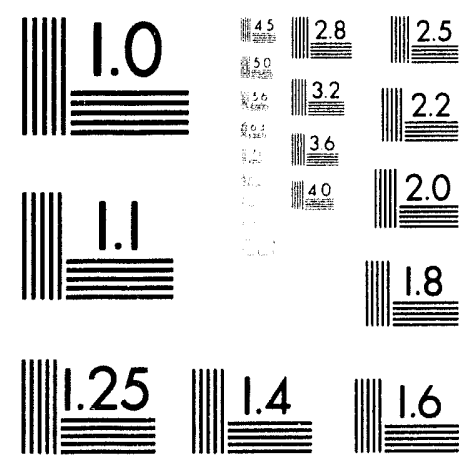



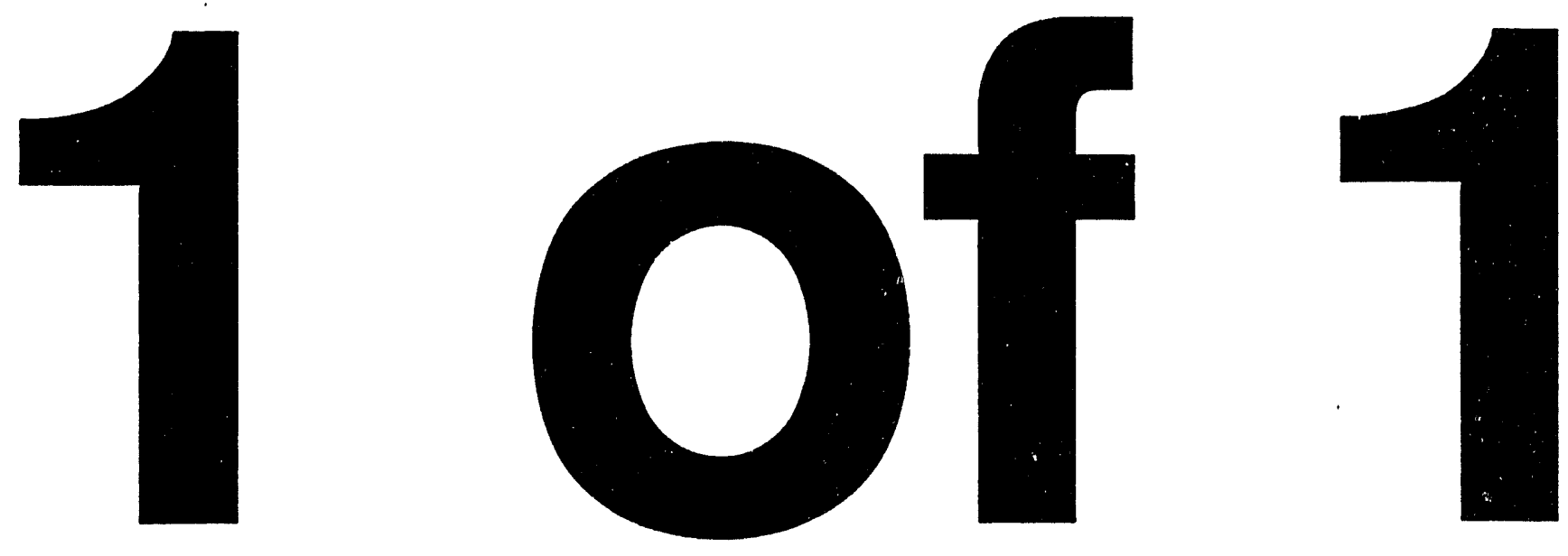
(1)

Hov 191633
OSTI
UCRL-ID 112774

Reprinted from Engineering Research, Development, and Technology.

Thrust Area Report FY 92

UCRL 53868-92

\section{Fabrication Technology}

\section{Kenneth L. Blaedel}

Narch, 1993

This is an informal report intended primarily for internal or limited external distribution. The opinions and conclusions stated are those of the author and may or may not be those of the Laboratory.

Work performed under the auspices of the U.S. Department of

Energy by the Lawrence Livermore National Laboratory under

- Contract W-7405-Eng-48. 
Disclaimer

This document was prepared as an account of work sponsored by an agency of the United States Government. Neither the United States Government nor the University of California nor any of their employees, makes any warranty, express or implied, or assumes any legal liability or responsibility for the accuracy, completeness, or usefulness of any information, apparatus, product, or process disclosed, or represents that its use would not infringe privately owned rights. Reference herein to any specific commercial products, process, or service by trade name, trademark, manufacturer, or otherwise, does not necessarily constitute or imply its endorsement, recommendation, or favoring by the United States Government or the University of California. The views and opinions of authors expressed herein do not necessarily state or reflect those of the United States Government or the University of California and shall not be used for advertising or product endorsement purposes.

This report has been reproduced directly from the best available copy.

Available to DOE and DOE contractors from the Office of Scientific and Technical Information P.O. Box 62, Oak Ridge, TN 37831

Prices available from (615) 576-8401, FTS 626-8401

Available to the public from the National Technical Information Service U.S. Department of Commerce 5285 Port Royal Rd., Springfield, VA 22161 


\section{Fabrication Technology}

Kenneth L. Blaedel 


\section{Fabrication Technology}

The mission of the Fabrication Technology thrust area is to have an adequate base of manufacturing technolegy, not necessarily resident at Lawrence Livermore National Laboratory (I.LNL), to conduct the future business of LLNL. Our specific goals continue to be to (1) develop an un-

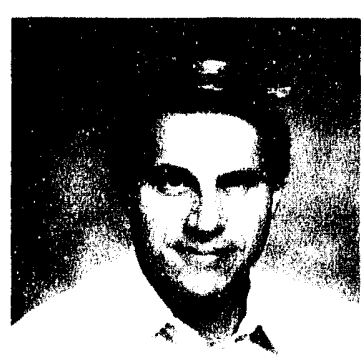
derstanding of fundamental fabrication precessises; (2) construct general purpose process models that will have wide applicability; (3) document findings and models in journals; (4) transfer technology to LI.NI programs, industry, and collengues; and (5) derelop continuing relationships with the industrial and academic communities to advance our collective understanding of fabrication processess.

The strategy to ensure our success is - changing. For technologies in which we are expert and which will continue to be of future importance to LLNL, we can often attract outside resources both to maintain our expertise by applying it to a specific problem and to help fund further development. A popularvehicle to fund such work is the Cooperative Research and Development Agreement with industry.

For technologies needing development because of their future critical importance and in which we are not expert, we use internal funding sources. These latter are the topics of the thrust area.

Three FY-92 funded projects are discussed in this section. Each project clearly moves the Fabrication Technology thrust area towards the goals outlined above. We have also continued our membership in the North Carolina State University Precision Engineering Center, a multidisciplinary research and graduate program established to provide the new technologies needed by high-technology institutions in the U.S. As members, we have access to and use of the results of their research projects, many of which parallel our own precision engincering efforts at LL.NL.

Kenneth L. Blaedel Thrust Aren Le'uter 


\section{Section 5}

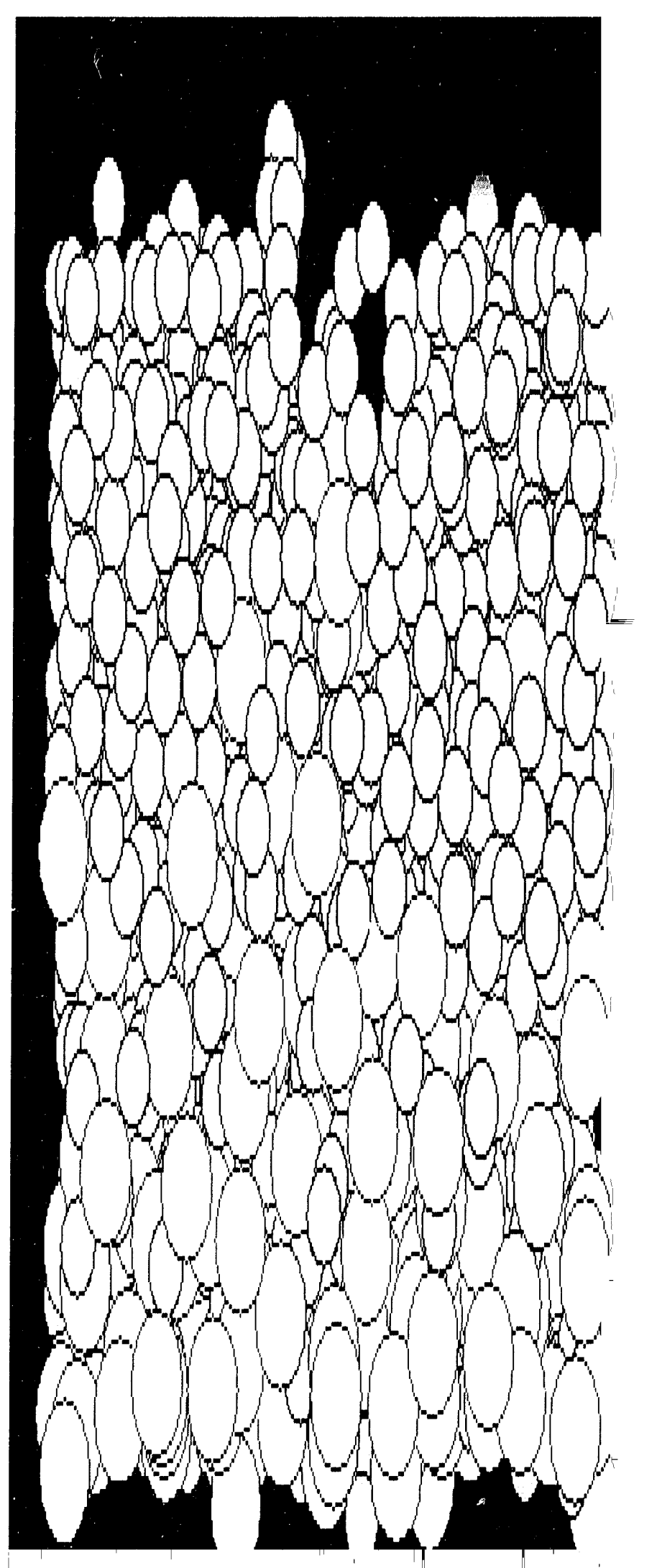




\section{Fabrication Technology}

\section{Overview}

Ke'mueth L. Blandel, Thrust Aren Linder

Fabrication of Amorphous Diamond Coatings

Steren Falabelln, Derid M. Simiters, and Darid B. Boercker.

Laser-Assisted Self-Sputtering

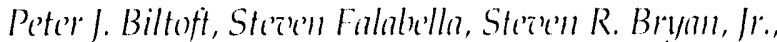

Ralph F. Poinlo, and Barry L. Olse'n

Simulation of Diamond Turning of Copper and Silicon Surfaces

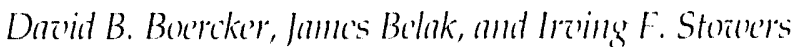




\section{Fabrication of Amorphous Diamond Coatings}

\author{
Steven Falabella and \\ David M. Sanders \\ Materials Fabrication Division \\ Mechanical Engineering
}

\author{
David B. Boercker \\ Condensed Matter Plyysics Division \\ Physics Department
}

Amorphous diamond is a hard, electrically insulating, inert and transparent form of carbon that has the $\mathrm{sp}^{3}$ bond character of crystalline diamond, but lacks a long-range ordered structure. The potential applications of amorphous diamond (a:D) are many. This material has several important advantages over conventional chemical-vapor-deposition diamond coatings, making it a more attractive coating for applications such as cutting tools, tribological surfaces, spacecraft components, and medical implarits. In FY-92, we produced carbon coatings with hardness rivaling that of natural diamond, and began to evaluate the use of this material in practical applications. We have produced amorphous diamond films on a routine basis, and have produced coatings up to $8 \mu \mathrm{m}$ thick on carbide tool bits. The combination of extreme hardness, low atomic number, smoothness, low friction, and low deposition temperature make a:D unique in the world.

\section{Introduction}

The physical properties of diamond make it an ideal material for many critical applications. However, natural diamonds are rare, expensive, and too small for many applications. A substantial amount of work is being done to produce diamond coatings on less expensive substrates, to take advantage of the properties of diamond without the need for large diamond monoliths. There are four critical problems that need to be solved before diamond coatings will be practical:

(1) Temperature of deposition. High process temperatures eliminate aluminum, tool steels, glasses, and polymers as possible substrate materials, limiting the usefulness of the coating. Also, heating and cooling of substrates adds time, complexity, and expense to the coating process.

(2) Adhesion to substrate. Thin films rely on the substrate for much of their mechanical integrity, depending on adhesion to the substrate for support. Failure of adhesion usually means unpredictable and rapid failure of the coated part.

(3) Stress. Internal stress limits the permissible thickness of a coating when the stress in the coating causes delamination or deforms the substrate.

(4) Smoothness of coating. In tribological applications, smoothness is essential for low friction and long life. Also, for optical coatings, any coating roughness will degrade the performance of the optic.

Diamond films produced by chemical vapor deposition have difficulty in all four areas. The adhesion is poor; deposition temperature is generally above $8000^{\circ} \mathrm{C}$; thermally induced stress is often excessive; and the polycrystalline films produced have high surface roughness, requiring expensive polishing.

The situation is very different for a:D. Amorphous diamond coatings are produced by the condensation of carbon ions on cooled substrates (at room temperature or below). They also replicate the substrate surface finish, and can be very adherent. We feel that only adhesion and stress are still problems, and may exclude the use of some substrate materials. However, an adherent interface can be created in several ways: a thin layer of a binder material can be deposited before coating with a:D; or, since the process is ion-based, substrate biasing can form a diffuse, adherent interface. Stress can be lowered by several means: 
increasing the incident ion energy by rf-biasing the substrate during deposition; increasing the substrate temperature; and incorporating impurity elements in the film. These methods to reduce stress and improve adhesion may also reduce certain qualities of the coatings, so tradeoffs will need to be made.

We have identified four areas where the extraordinary properties of a:D con have a large impact. The first is the coating of tool bits for use on diamond turning machines to exploit the toughness, adhesion, hardness, and wear resistance of a:D. If successful, this process will lead to cost savings where the surface finish and precision required is less than that produced by dianond turning, yet better than can be produced by conventional cutting bits. At present, the finish obtained on a part is limited by the edge quality of our coated carbide bits, which in turn is limited by current polishing methods. If a better method can be found to form the tip radius of a coated bit, geometries and precision not practical with natural diamond could be achieved.

Second, the surfaces of metrology blocks, caliper faces, and precision slides can be coated and polished to provide hard, smooth, and wear-resistant surfaces that will not change dimensions or scratch the parts under test. This will allow more confidence in the continued accuracy of the tools, save re-calibration time, and prolong the life of the equipment.

Third, there are applications that would benefit from the tribological properties of a:D, in air and in vacuum. The friction coefficient for a:D is measured to be 0.2 or less in all conditions. There are several important areas where a long-life solid lubricant could have prevented the failure of mechanical systems on spacecraft, and would enable new mechanisms to be practical in spacecraft. A representative example is the Galileo probe's main antenna that failed to deploy due to the failure of the $M o S_{2}$ lubricant on its opening mechanism. Coating both disk surface and heads will reduce the damage caused by 'head crashes' and may enable magnetic recording media of higher density by allowing smaller head-to-disk distance.

Finally, there are several applications of a:D in the medical field. Due to the wear resistance and biocompatibility of a:D, the potential is great for coating scalpels, replacement-joint wear surfaces, and other implanted parts. If a suitable technique is developed to allow a coated blacte to achieve the sharpness of a natural diamond scalpel, the potential benefits would be tremendous. Incisions made by diamond scalpels heal up to five times faster than those made with steel blades, reducing recovery times (and hospital costs) for many surgical procedures. The high cost of diamond scalpels (several thousand dollars each) is now the main limit to their use.

\section{Progress}

In FY-92, we produced carbon films with our filtered cathodic-arc system, which was developed in previous years. The cathodic-arc source produces a carbon ion beam from a graphite target, in a high vacuum environment. ' Our goals for the year were to investigate the conditions under which a:D is formed, to improve adhesion to various substrate materials, to model the deposition process using molecular dynamics (MD), and to reduce residual stress in the films, which is required to deposit greater thicknesses.

We installed a cooled and biasable holder to control the substrate temperature during deposition. Initially, the holder was cooled by liquid nitrogen, but we found that water cooling produced equivalent results. By using a high-voltage bias for the first few seconds of coating, we have produced coatings on cemented carbide tool bits with adhesion above $10 \mathrm{kpsi}$ (limit of the Sebastian pin-pull tester). We are investigating methods that will measure adhesion to higher values.

We were able to achieve hard carbon coatings that are low in hydrogen content. The hardness of carbon films is inversely related to the hydrogen content; e.g. 10 to $20 \%$ hydrogen in a carbon film (known as diamond-like-carbon, or DLC) reduces the hardness by a factor of four. The hydrogen content of our coatings was measured to be less than $0.1 \%$, using forward recoil scattering (FRS). We determined the density of our films from the areal density obtained, using Rutherford backscattering (RBS) and the film thickness. We measure the density of a:D to be 2.7 $\pm(0.3 \mathrm{~g} / \mathrm{cc}$, which is between graphite at $2.26 \mathrm{~g} / \mathrm{cc}$ and diamond at $3.5 \mathrm{~g} / \mathrm{cc}$.

One of the most appealing properties of amorphous diamond is its extraordinary hardness. However, standard hardness tests made by indenting are generally difficult to interpret when the coating is thi: and harder than the substrate material. To get a true measurement of the coating hardness, the indent depth must be less than 7 to $20 \%$ of the coating thickness. ${ }^{2}$ Quantitative hardness tests are in progress with an ultra-microhardness tester, which uses such a small indent that the measurement is not influenced by the substrate. A standard Vickers indent of a tungsten carbide tool bit coated with $8 \mu \mathrm{m}$ of a:D with loads up to $500 \mathrm{~g}$ gives a hardness of $10,000 \pm 10 \%$, the same as 
natural diamond. At 50)( ge the indent depth is 17"0. To put the severety of this test in perspective: the stress put on the film at the $5(0)$-g load is over $17 \times 10$ (1) psi. lor thimmer ontings, the Vickers test gives a hardness abose 5()$(0)$ at low indent loads (25 g) and then decreases, as the load increases to roughly the substrite hardness value (hardnessiof tungsten carbide is 2 2(x)( $\left.1 / \mathrm{H}_{\mathrm{V}}\right)$. To get another assessment of the hardnessi, we used an abrasion test. We assessed the hardness of the a:D contings that we produced, by abrading various hard materials against a coated plate. We were able to polish facets in all materials attempted, including matural and synthetic diamond, indicating that the coating is approximately as hard as diamond. This may point to yet another applicatior:, i.c., the surfacing of coramic, ore eren diamend tools.

The greatest difficulty wilh a:l) films is their high intrinsic stress. ()ur filtered outhextic-arc source produces a fully ionized beam of carbon with a mean energy of $22 \mathrm{CV}^{3}$, and produces stress levels of 6 to 10 (i) a. This com be reduced by increasing the incident ion energy impinging on the stabstrate. Wo used a 1.3.56-MH lorf supply to providea bias during depesition. Since the films produced arenon-conductive, ribias is reguired to maintain the potential at the film surtace during conting. We have reduced the intrinsic stress in a:1) films by a factor of two using bias alone, and by a factore of five using a combination of bias and the incorporation of $7^{\prime \prime}$ " nitrogen in the films. $\wedge$ plet of the residual stress vis bias voltage on the substrate (I) level) is shown in Fig. 1. (oatings with and without nitrogen are show' Although residual stress is reduced by the addition of nitrogen, the mea-

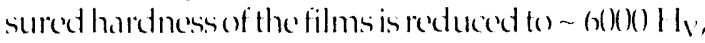
as noted above. Residual stress was inferred from the bowing of two-inch silicon wafers. () n carbideforming materials, the athesion is sulficient to produce thick contings, without delamination of the coating caused by the compressive stress, as long as the bias voltage is kept above 150 V during deposition. The 8 - $\mu$ m-thick coating produced on a tungsten carbide tool bit was limited only by source material depletion.

The fine structure of a:D) was characterized by TY:M and electron diffiaction. TKM showed no evidence of any ordered structure down to $10 \AA$, indicating its amorphous noture. Unlike natural diamond or Dl $(;$, a: 1 ) has a flat transmission specetrum from $0.810>5() \mu \mathrm{m}$, which is due to its amorphous mature and the lack of hydrogen. The transmission of a free-standing film was measured using a FTIR spectrophotometer. From the interference between the front and back surfaces and

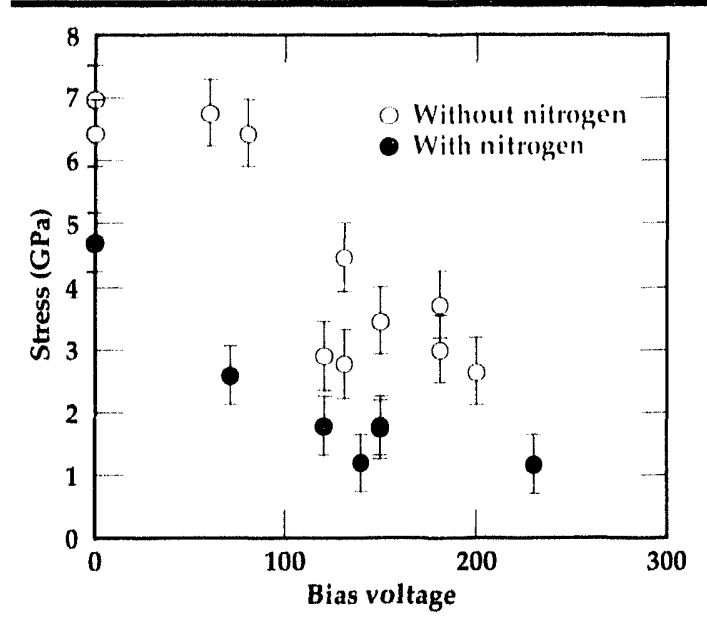

Figure 1. The intrinsic stress in amorphous diamond films vs bias voltage. Stress is reduced substantially by the addition of bias during deposition, and even further by the addition of nitrogen. Data taken with no nitrogen during deposition are in open circles; data taken with a nitrogen background are in solid circles. In both cases, the stress reaches its lowest value around $150 \mathrm{~V}$ and is roughly constant above that value.

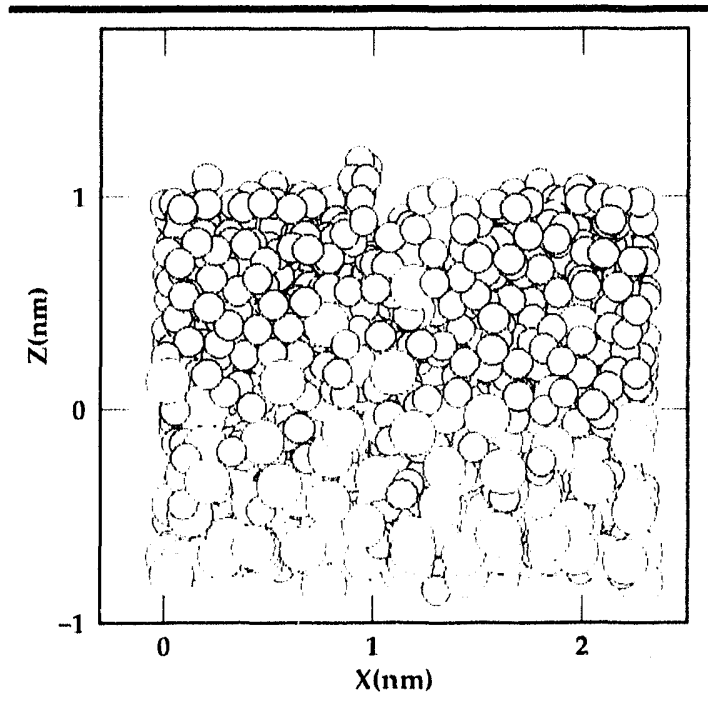

Figure 2. A molecular dynamics simulation of $20 \mathrm{eV}$ carbon ( 880 atoms) impinging on a silicon surface. Substantial mixing occurs at the interface. The carbon atoms are shown as dark gray circles; the silicon atoms are light gray. The view is parallel to the original silicon surface.

the measured thickness of the films, we determined the index of refraction of eur a: 1 ) to be in the range 2.t7 to 2.57. This is dese to 2.42, the refractive index of natural diamond.

Using MD simulations, we have modeled the condensation of carbon atoms onto a silicon substrate to see the effects of deposition energy on conting structure and stress. Figure 2 shows carbon depessited on a silien surface. firen at the deposition energy of $20 \mathrm{CV}$, there is substantial 
mixing at the interface. We are now using the code results to interpret the electron diffraction measurements. By Fourier transforming the atom positions in the simulation, we were able to closely match the olaserved positions of diffraction rings.

\section{Future Work}

We have described only a few of the possible applications of a:D, with others to be realized as the material becomes better characterized. Theoombination of extreme hardness, low friction, smoothness, and low deposition temperature make amorphous diamond a unique and very promising material.

The next step in the development of this material would be to test our amorphous diamond films in practical applications. However, we have not yet obtained continued funding for this project.

\section{Acknowledgements}

We wish to thank R. Musket for providing the RBS and FRS measurements; R. Chow and G. Loomis for the optical measurements; M. Wall for the TEM and electron diffaction work; J. Ferriera for the hardness tests; J.H delpruneda for insight into medical applications; and the Vacuum Processes Laboratory staff for their technical support.

1. S. Falabella and D.M. Sanders, 1. Voci, Sici. and Tirlmol. $A 10$ (2), 394 (1992).

2. C. Feldman, E. Ordway, and J. Bernstein, J. Vac. Sci. and Tidluol. $\wedge 8(1), 117(190)(0)$.

3. I.J. Martin, S.W. Filipozuk, R.P. Netterfield, I.S. Field, D.F: Whitnall, D.R. McKenzice, I. Moter: Sit. l. $11.7,410(1988)$. 


\section{Laser-Assisted Self-Sputtering}

\author{
Peter J. Biltoft, \\ Steven Falabella, \\ Steven R. Bryan, Jr., and \\ Ralph F. Pombo \\ Materials Fabrication Division \\ Mechanical Engineering
}

\author{
Barry L. . Olsen \\ Materials Division \\ Chemistry and Materials Science Department
}

Our goal for FY-92 was to ctemonstrate laser-assisted self-sputtering as a method for sputter deposition of thin film coatings in a high vacuum environment.

\section{Introduction}

Our experimental program was designed to investigate merging the technology of magnetron sputteringl and laser ablation ${ }^{2}$ to create a wellcontrolled deposition process free of the need for a process gas. Self-sputtering of copper, using a conventional magnetron sputter gun, has been reported. ${ }^{3}$ In this process, a glow discharge plasma was initiated by operating a magnetron in the conventional manner, with argon as the process gas at a pressure in the range of from 5 to $20 \mathrm{~m}$ Torr. After the plasma was well established, the process gas pressure was slowly reduced. As this was done, sputtering was maj' tained by ionization of sputtered copper atoms in close proximity of the cathode. We hope to demonstrate self-sputtering initiated by a laser-induced plasma in the absence of any process gas.

\section{Progress}

Our first goal was to design and build a fixture that would accommodate installation of a

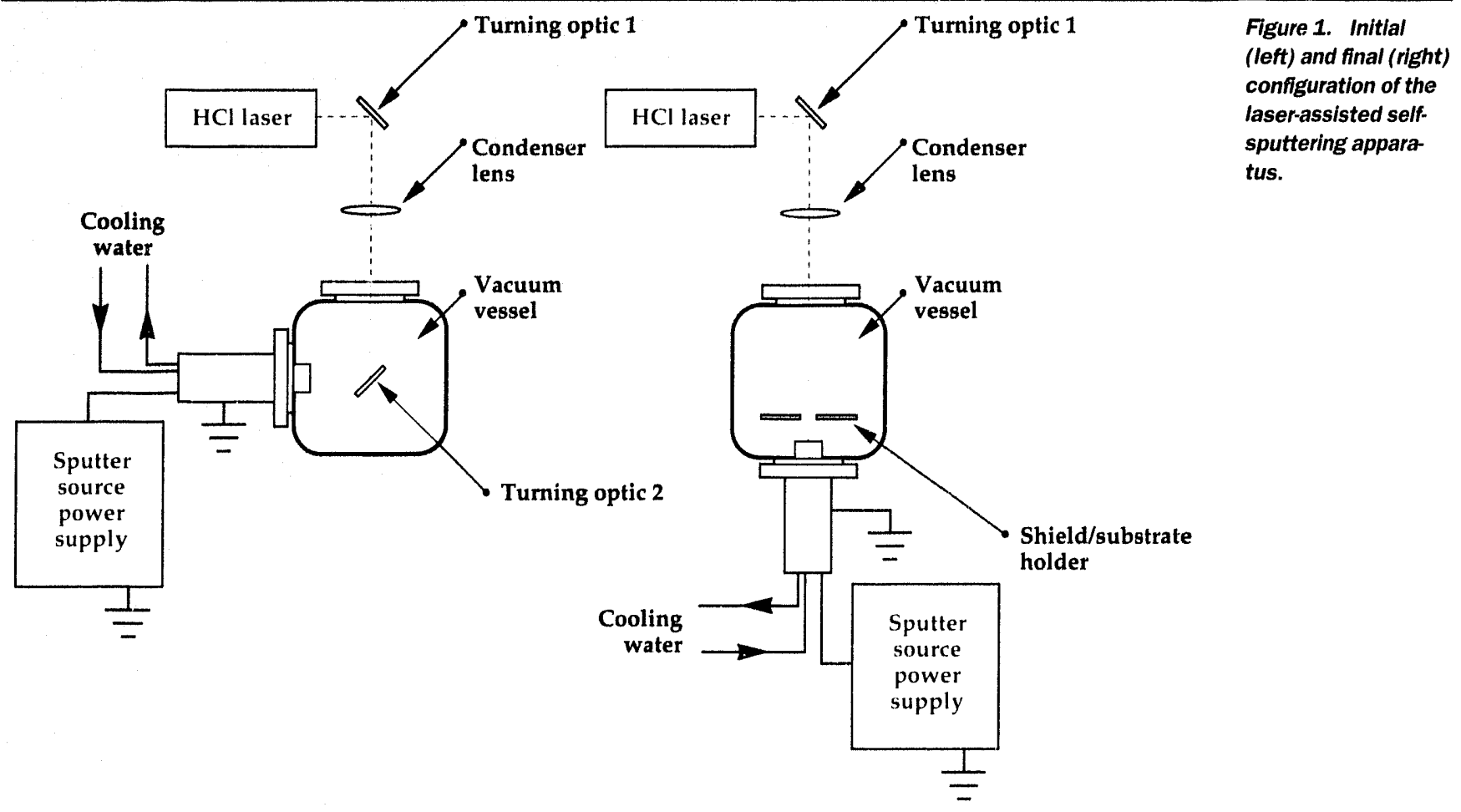


conventional magnetron sputter gun into an existing racuum ressel designed for thin film growth by laser ablation. We selected a small, commercial, sputter-deposition source (2-in. US gun) for our first evaluation. A schematic of the experimental apparatus is presented in Fig. 1 (left). Initial deposition runs were conducted at pressures below $5,10^{-5}$ Torr, as measured using a hot cathode ionization gauge on the racuum ressed. We used a pulsed-output $\mathrm{HCl}$ laser operating at a wavelength of $308 \mathrm{~nm}$ to initiate the plasma. Typical operating parameters for the laser were 1- to 1()-H\% repetition rate and 16()- to $32(1)-\mathrm{m} J$ pulse power. The laser beam was de-magnified using a $5(0)-\mathrm{mm}$ focal length, plano-convex lens external to the racuum vessel. Powerdensit" at the sputter source cathode was between 21 and $42 \mathrm{~J} / \mathrm{cm}^{2}$. A high-output power supply designed for magnetron sputtering was used to bias the cathode to $-\overline{7}(0) \mathrm{V}$. While we were able to briefly maintain a plasma at the sputter source, we discovered that the laser damaged tuming optic 2 rapidly, reducing the pow'er densits we were able tordeliver to the cathode. To rectify this problem, we reconfigured the apparatus as shown in Fig. 1 (right). In the seeond configuration, we were able to initiate and maintain indefinitely a toroidal plasma at the sputter target. The color of the plasma for the copper target was bright green, indicating the presence of high concentrations of copper species in the plasma. ' Ling this setup, we deposited several thin filmosif copper. During 10-minute deposition runs, the magnetron power supply outputs indicated that the peak voltage was $500(\mathrm{~V})$ and arerage current was (0.1 $\mathrm{A}$.
Using a storage oscilloscope, we observed that the violtage output of the magnetron power supply was reduced almost to zero following every laser pulse. In an effort to deliver higher current to the sputter source, we installed a (0.1 $\mu \mathrm{F}$ : capacitor capable of operating at $>5 \mathrm{kV}$, between the magnetron sputter supply and the sputter source. No appreciable benefit was realized through this modification.

\section{Results}

We have deposited thin films of copper, aluminum, and tantalum by laser-assisted self-sputtering in a high vacuum environment. Deposition rates for the copper films were observed to be greater than $0.1 \mathrm{~nm} / \mathrm{s}$. This repiesents an increase in deposition rate of greater than a factor of 30$)$ compared to pulsed-laser deposition of copper under identical circumstances.

\section{Acknowledgements}

We would like to thank Veil lound, who designed and built the hardware used in this work, and Bob Tench for his assistance with the $\mathrm{HCl}$ laser.

1. J.I. Vessen and W. Kern, Thim I ilm Pronesese, Academic Press, Inc. New York, Vew Yorkj, 1978

2. D.B. Chriser and A. Inam, Mate's. Re's. Billl., 37 (February 1992).

3. R. Kukla, I. Krug, R. I.udwig, and K. Wilmes, Viatum R. $41(7-4), 1968(14901)$.

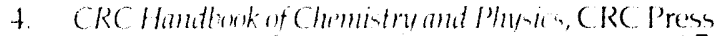
(Bera Ratun, Horida), 1990). 


\section{Simulation of Diamond Turning of Copper and Silicon Surfaces}

\author{
David B. Boercker and \\ James Belak \\ Condensed Matter Physics Division \\ Physics Department
}

\author{
Inving F. Stowers \\ Precision Engineering Program \\ Engineering Directorate
}

We have applied molecular dynamics modeling to the diamond turning of a ductile metal (copper) and a covalent material (silicon). On the nanometer-length scale, both materials show ductile behavior, but the atomistic me-hanisms that allow the behavior are significantly different in the two cases. In addition, we studied the wear of small diamond asperities while they machined a silicon surface.

\section{Introduction}

Diamond turning is, by now, a well established technique for machining high-quality surfaces with dimensional tolerances of a few tens of nanometers. This technique is particularly successful when applied to non-reactive, ductile metals such as copper. It is less useful when applied to carbideformers, like iron, or to brittle materials. Tribochemical reactions can cause excessive tool wear, while brittle fracture produces surface damage. Recently, there has been interest in diamond turning silicon to obtain precisely shaped optical substrâtes. In this case, both problems occur. Silicon is a strong carbide former, and it is a covalently bonded, hard material that is prone to fracture.

To gain insight into the atomistic mechanisms of importance to diamond tuining and to diamond tool wear, we have performed molecular dynamics (MD) simulations of the machining of both copper and silicon surfaces with diamond tools. The basic MD method is the same as that used previously 1 to simulate orthogonal cutting and nano-indentation. The simulations are performed in the rest frame of the cutting tool and follow the detailed, microscopic motions of the atoms, both in the tool and in the work piece, as it moves under the tool. Such simulations give good qualitative descriptions of chip formation and dislocation propagation.

The central input to the simulations is an appropriate interatomic force law. In the copper simulations, we use the embedded atom potential ${ }^{2}$ for the interaction between two copper atoms, while the atoms in the diamond tool are assumed to interact with the metal atoms through a LennardJones potential. For the silicon simulations, we have implemented interatomic potentials for silicon and carbon, ${ }^{3}$ which include angular-dependent forces that are very important in covalent materials with low coordination. Interactions between like and unlike atoms are included in this model.

\section{Progress}

We have performed two types of simulations, each designed to look at a different aspect of the problem. One class is designed to simulate orthogonal cutting and to focus on chip formation and mechanisms of plastic flow. The other looks in detail at possible wear mechanisms, such as graphitization and carbide formation, for the tool.

In both types of simulation, the work piece is a large slab containing tens of thousands of atoms oriented with a specific crystal direction face up. Most of the atoms in the work piece move freely according to Newton's laws. Relatively few atoms near the upstream boundary and the lower boundary have additional constraint forces that maintain their temperature at a constant value, ${ }^{4}$ allowing heat generated at the tool tip to flow out of the system. Finally, a constant velocity boundary condition is imposed on the lowest atoms in the slab. Atoms leaving the simulation cell at the 'downstream' end are destroyed, and new ones are periodically produced at the 'upstream' boundary. Performing the calculation in the rest frame of the 


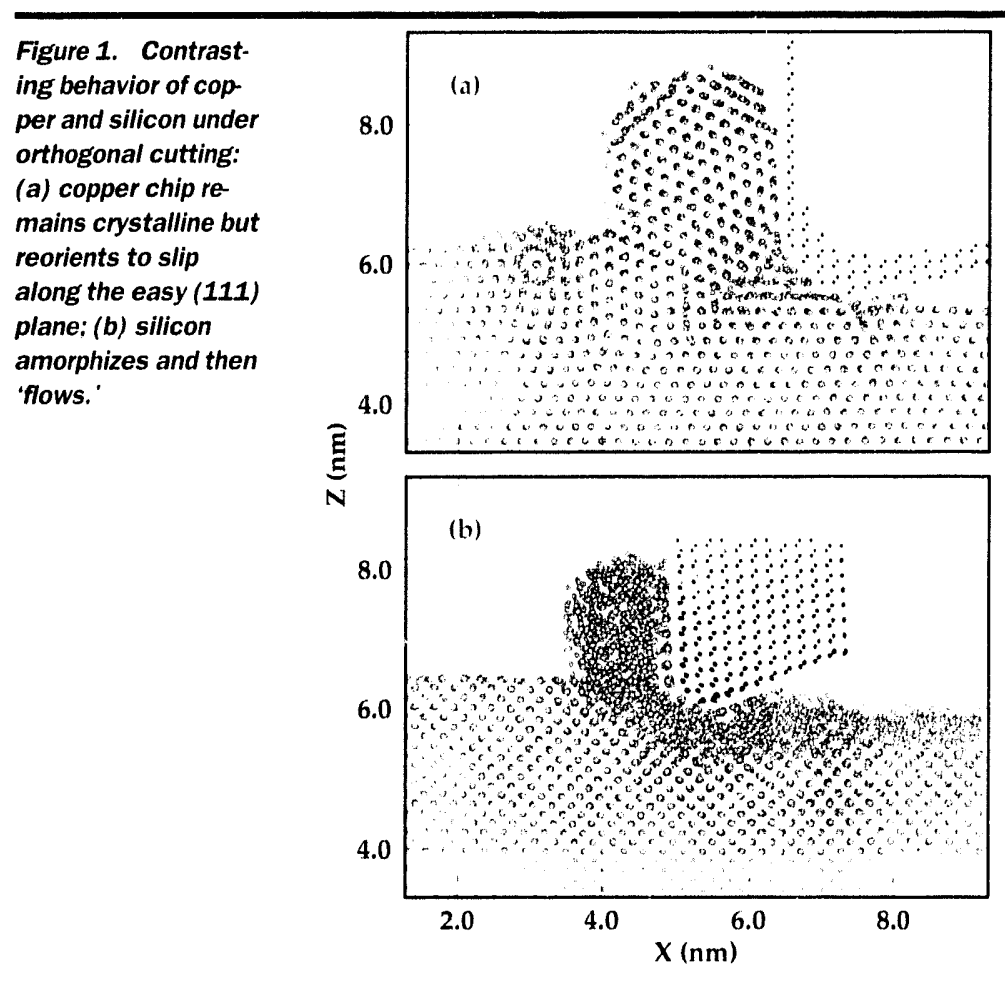

toot allow's the simulation of cutting oxer lengths that are many times the computational cell dimension, without having to follow the motion of a prohibiticely large number of atoms.

\section{Orthogonal Cutting}

We simulated diamend luming in the (o) thengenol cutting geomedry becreating a wedge-shaped tool with a close-packed (111) cutting face, and imposing periodic boundary conditions in the direction parallel to the surfice and normal to the cutting direction. In the case of coppere, the diamond tool comprised a rigid array of atoms with about a $2 \mathrm{~nm}$ radius of corrature. The work piece contained $36,(0)$ () copper atoms with the (111) fare up, and mored under the tool at a speed of about $10(0 \mathrm{~m} / \mathrm{s}$ from left to right. A cross-sectional snapshot' of the simulation is shown in Fig. 1a. From this picture, we notice that the chip has remained corstalline, but it has been reoriented to form a (111) slip plane in the primary shear ane in front of the tocol.

In contrast to the copper simulation, the silicon calculation allow's the lower atoms in the $t(x)$ to mose according to their force law's, and onle the uppermost atoms are held rigid. Atoms just below the rigid lavers are maintained at onnstant temperature. The weok piece consisted of 2()$, 1(x)$ atems with the ((x)1) plane face up, moxing at about $5+1) \mathrm{m} / \mathrm{s}$, left to right. A cross-sertional 'smapshot' of this simulation is show'n in Fig. 1b. The first thing to notice is that both the chip and the cut surface are amorphous. In addition, there appears to be a boundary layer of silicon clinging quite tightly to both the rake and dearance faces of the t(x)l.

\section{Tool Wear}

Tocel wear was simulated by suspending two small carbon asperities from a flat diamond surface and observing their interaction with the silicon work piece. The asperities differed in size, but were both shaped as square pyramids with the four triangular faces being (111) surfaces. The square base of the larger pyramid contained $6+(=8 \times 8)$ atems, while the base of the smaller one contained $36(=6 \times 6)$ atoms. All of the atoms in both asperities were free to move as Newton's equations dictate. The bases of the pyramids were (0)(01) planes attached to the bottom (0)(01) plane of rectangular diamond shab, four atomic layers thick. The atoms in the bottom two layers of the slab also moved according to Newton's equations, but tl eir temperature was controlled. The atoms in the tepp two lavers were kept in a rigid lattice that initially moved downward at a constant velocity, but stoppedafter the desired penetration was obtained. After that time, these atoms were held fixed in space. Soren after the asperities made contact with the silicon, the atoms in their tips began to break away, and some were replaced by silicon. Later in the simulation, a graphitic cluster of six carbon atems appeared at the surface on the downstream side of each asperity. No other damage to the asperities, except for a build-up of silicon on the pyramid faces, was visible during the simulation time of about 10 ps.

The central result of this work is the contrasting beharior of our prototype materials, copper and silicon, under orthogonal cutting. Copper forms a face-centered-cubic (foc) orystal with a single-atom basis. As a result, slip along the close-packed (111) planes is analogrous to sliding stacks of marbles orer erach other, and as seen in Fig. 1a, the copper chip remains crystalline, but reorients and slips along the casy plane. In contrast, silicon forms a diamond lattice that is also fice, but contains a twoatem basis. Conseyuently, sliding aleng the (111) plane is hindered by the strong angular forces, and Fig. 1b shom: that silicon amorphizes and then 'flow's.' This suggests that the surface selects the state that minimises the work done by the tool.

Our simulation of the wear of small diamond asperities while cutting silicon showed evidenoe 
of both 'graphitization' and carbide formation. Six carbon atoms broke off the asperities and formed hexagonal rings, while silicon atoms filled the resulting vacancies by bonding strongly to the diamond.

\section{Future Work}

The ability to understand and control the ductile-brittle transition in glass is critical to improving the economic viability of the state-of-the-art machining capabilities being developed at Lawrence Livermore National Laboratory (LLNL). Our next objective is to define the mechanisms of microplasticity and damage initiation in fused silica by using MD techniques, to follow changes in the structural properties and the dynamic interactions of the atomistic glass network. We hope that an explicit demonstration of the ability to model these processes will greatly enhance the competitive- ness of LLNL's materials fabrication efforts within the Department of Energy and elsewhere.

1. J. Belak and 1.F. Stowers, "Molecular Dynamice Modeling of Surface Indentation and Metal Cut-

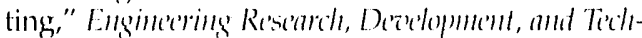
nology, I awrence Livermore National Laboratory, Livermore, Californis, UCRL -53868-91, 4-3(1992).

2. D.J. (Oh and R.A. Johnson, "Embedded Atom Method for Close-l'acked Metals," Alomistic Simmlation of Materinls: Beygent Pair Potenlinals, V. Vitek and D.J. Srolovity (Eds.), Plenum Press (New York), $233(1989)$.

3. J. Torsoff, l'/l/s. Re'c. B 39, 5566 (1989).

4. W.C. Hoover, M/hys Rere A31, 1695(1985).

5. D.B. Borercker, J. Belak, I.F. Stowers, R.R. Domaldsom, and W.I. Sickhaus, "Simulation of Diamond Turning of Silicon Surfaces," Proc. ASPE 1992 Ammunl Me'ling (Cirenclefe, Florida), 45 (October 18-23, 1942). 

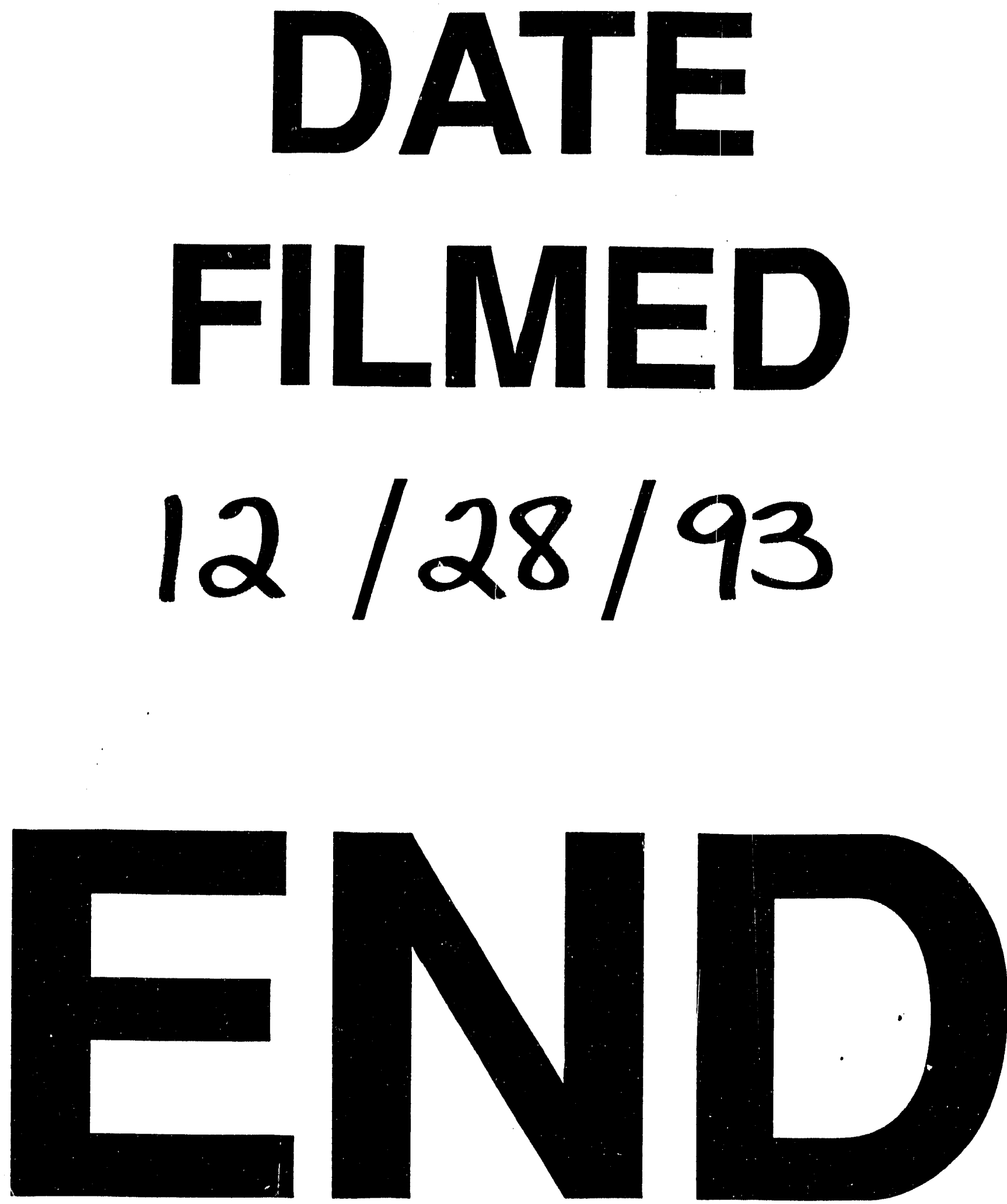
